\title{
A View of Teaching Writing Ability at High-School: An Effect of the National High-School Graduation Examinations
}

\author{
Binh Nguyen Thi Xuan ${ }^{1,2}$
}

\author{
${ }^{1}$ Faculty of Foreign Languages, An Giang University \\ ${ }^{2}$ Vietnam National University Ho Chi Minh City, Vietnam
}

\begin{abstract}
With the effort of renewing the National examinations to increase testing accuracy and fairness over the last decades, the Ministry of Education and Training of Vietnam has applied multiple-choice format to many subjects in which English is included. However, in the realm of writing assessment, the most controversial questions have been arisen that "Can multiple-choice testing format assess students' true writing ability?", and "Has multiple-choice testing format affected the teaching writing ability at high-schools?" Within the framework of this article, the writer desires to associate the testing formats of English through the HGEs along with viewing the required tasks of writing skill by means of reviewing textbooks currently used, in order that appropriate recommends should be concerned.
\end{abstract}

Keywords:High-school Graduation Examinations, writing ability, objective testing (ex. multiple-choice format), subjective testing (ex. written format).

Abbreviations:

HGE:High-school Graduation Examination MOET: Ministry of Education and Training

\section{Introduction}

Writing is considered as manifestation of human beings through language for its distinction between textual and non-textual medium of inhuman. This has been proved by archeologists and linguists who observed the ancient illustration like as cave drawing and painting. Thus, it is admitted that the ability of organization a text brings out the existence of people in a developed community. In other word, only people in this world can develop the system of language, and writing system is one of the most central features of language. To Ager (1998, par.1), "Writing is a method of representing language in visual or tactile form. Writing systems use sets of symbols to represent the sounds of speech, and also have symbols for such things as punctuation and numerals."

Besides, writing is a special way of communication among the people firstly having the same writing system with the implication that they are in an organization or a community, it is because writing stands for a great formality holding numerous principles as well as rules in it whenever writers organize their thoughts.

In short, writing is the highest development of a language of which it completely covers the whole features.

It is, nevertheless, sad but true that the training process in the high schools in Vietnam mainly aims at examinations, that is to say teaching and learning what will be tested. Therefore, the consequence of this tendency has negative backwash on students and even teacher as they only focus on the test format known as multiple-choice; as a result, students cannot achieve the proficient ability of English, especially speaking and writing skills. Over the years teaching at An Giang University, I have recognized that most freshman students majored in English have not performed their writing ability well. The possible explanation for this problem is that these students had concentrated too much on multiple-choice testing which has been the main testing format applied in HGEs.

\section{Review of Literature}

The ways of assessing a student's writing ability always attract attention of educators, and the choice of test type depends on the objectives of a test on the ground of their nature as "the subjective type of test allows students to write and use language in their answers while the objective type does not." (Tunku, 2000). 


\section{Objective testing:}

In Vietnam, objective testing (the most common questions are multiple-choice, true/false, matching items, and completion) has been used for its advantages manifested under scoring issue, in which the scoring process is conducted objectively by following a consistent answer or by scanning machines and computers. However, this testing has its own disadvantages as it is said to embed more guessing factors; especially, this kind of test has a severe effect on English-majored students (at University or College) for lack of writing ability. This result is of the true that students were not trained with adequate ability in high school because of being prepared for examinations (mostly under multiple-choice and sentence writing exercises which mainly focus on grammar) rather than being established with sufficient knowledge to further studying.

In addition, some advantages of this type are also known as time consuming to write good items, objective scoring, but less valid than subjective test, and no suitability for assessing certain abilities. Despite being a controversial topic, it still remains popular due to its utility, reliability, and cost effectiveness.

\section{Subjective testing:}

Contrasting with objective testing is subjective testing which requires the test takers to write and present an original answer, including short-answer essay, extended-response essay, problem solving, and performance tasks (Zimmaro, 2003, p.15).

For good side, subjective tests represent their strongest point under face validity which allows the test takers to perform their actual ability. Students can demonstrate written expression in such a logical order that their results are precisely measured. Beside that, learners' language knowledge is assessed in a wide range including mechanics, grammar, style, ideas organization, and logical development. It is clear that these fields of knowledge are unable to be shown in objective tests since they are kind of discrete language properties assessment (emphasizes on mechanics, grammar, and vocabulary only) while other significant aspect of written language (organization, content, and coherence) are ignored.

The biggest drawback of subjective test revealed under its name is the variation in marking which is shown that "experienced examiners award widely varying marks not only on the same piece of work marked by other examiners, but on their own marked scripts re-marked after a passage of time" (Zimmaro, 2003). According to her, this format has been criticized to base on the basis of loosely defined criteria with lack of consistency from one reader to another, and grading is time-consuming and often impractical in large numbers. On the other hand, such examinations have been thought to be deficient in consistency because of essay writing; besides, over-burdened staff, time-consuming and financial problem are considered the big dilemma to make the exam impractical as well. Although it is not the best way to assess student's writing ability, subjective form is still able to gain both validity and reliability when issues of administration, testing conditions, population factors, and scoring are under appropriate attention and adequate control (Huot, 1990).

\section{Discussion}

It is admitted that testing and evaluation is one of the most important stage of education since it has strong impact on teaching and learning process. Based on this acknowledged role, the MOET made an enhancement to the field of measurement and evaluation systems that is actually the nature of innovation to the nation-wide examinations along with serious formative assessments at school. In Vietnam, HGE is held under supervision of the MOET, hence the MOET's project tends to affect it with the change of examinations, particularly in test format.

For innovation in education, there was a change of test form from the 2006 to 2013 HGEs in which multiple-choice testing format (with four choices A, B, C, D) was entirely applied to English, instead of partly being designed in the previous test structures, and therefore, written form was rejected completely. As declared by Dr. Vu (2007), a trend of using multiple-choice testing in most crucial examinations would become predominant in Vietnam for its progress considered as a modern scientific study.

Following is the presentation of the test structures under 50 multiple-choice questions with 5 choices (Note: just focus on test format, not test content) through 2006 - 2013.

1. PHONOLOGY

- Word stress/ Ending sound/ Vowels or Consonants: Odd one out.

\section{VOCABULARY, GRAMMAR}

- Filling the blanks of the sentences by choosing the best options (Comprising: tensesagreement, sentence structures, connectors, prepositions, word choice, simple communicative functions, etc.)

\section{READING SKILL}

- Filling the blanks of the passage by choosing the best options.

- Reading comprehension.

4. WRITING SKILL

- Completing the sentences by choosing the best options (sentence level)

- Choosing the answers which are closest in meaning of the original sentences.

- Mistakes recognizing.

The MOET, however, subsequently seemed to make a great fuss when trying to apply various 
formats in the English test of HGE 2014 with 30 multiple-choice questions for the objective format and writing a paragraph for the subjective one. Most students found confused and were not all prepared with writing skill as this format had just been embedded into the exam after many years familiarizing with entirely multiple-choice test format. Yet, for the HGEs 2015 and 2016, the English tests were designed with 64 questions for the Multiple - choice section and writing for the Writing section (both sentences and paragraph writing).

Since 2017, the English test format of HGEs has changed again, similar to the previous format with 50 multiple-choice questions in the HGEs before 2014. In basic, each test includes:

- Reading comprehension: 15 questions

- Grammar and Vocabulary: 12 questions

- Gap filling: 5 questions

- Writing sentences which are closet meaning in the given sentences: 5 questions

- Phonology: 4 questions

- Synonym, Antonym: 4 questions

- Recognizing Mistakes: 3 questions

- Communicative language: 2 questions

Through the continuously changing of testing formats of English as mentioned above, teaching writing in most ofthe high schools in Vietnam has beenconsequently shown under techniques at sentence level, mainly focusing on following main types of exercise (collected from the textbooks of English for high-school level, published by Viet Nam Education Publishing House):

- Completing the blanks in a paragraph with the given words (using the correct form of the words).

- Completing/ rewritingthe sentences in such a way that they are as similar as the meaning of original sentences.

- Writing complete sentences using suggested words/ phrases based on the required structures, or in their correct forms.

- Explaining the original sentences by sentence transformation.

- Using prompts to make up complete sentences about a given topic or rearrange sentences to make up a complete paragraph.

- Completing sentences by matching the two halves of a sentence.

- Using the suggested ideas to complete the essay.

Although paragraph writing and essay writing included in the textbooks of English, they have seemed to be neglected in most high schools for the reasons of time-consuming and not-being used form in HGEs, in which the English exam has 50 multiplechoice questions without including speaking, listening or writing tests. As a result, the current teaching style of English in most high-schools focuses only on structure and grammar so that the students are able to get high marks in the HGEs.
ISSN 2455-6378

\section{Conclusions}

For the purpose of obtaining proficiency in teaching writing capability at high-school, the best way to assess writing ability should be a combination of testing formats comprising subjective and objective testing. The strong and weak points of each format lead to various opinions in deciding which test type should be applied to obtain a valid and reliable test of writing ability. Besides, the history of testing passed through movement from subjective to objective testing with presenting both strengths and weaknesses, thus most testers tend to find out a better sample with the best features of these two extremes, that is to say, the strong points of the two should be included as overall content of the subjective format in written tests and consistent objective scoring of the objective one in multiplechoice tests.

It is also obviously reported in some studiesby Educational Testing Service (ETS)that there existed this approach in their tests. That the more reliable essay scores were not aimed to but a unique kind of information would be provided for the purpose of public reporting based on the viewpoint that a sole test can be reliable when considered along with other information.

Another recommendation has been suggested according to the particular traits of Formative Assessment and Summative Assessment for both instructional and administrative purposes. Formative assessment should be implicated as classroom (or processing) assessment in which both multiplechoice and sentence or essay writing can be used to improve students' writing ability during the teaching and learning process in high school. Whilst, Summative assessment is considered as HGE which Multiple-choice testing is employed for the purpose of financial issue and reliability. From that point, the combination of results achieved from high school and final exam may be more accuracy and valid; moreover, students will be more proficient in writing ability.

\section{References}

[1] Ager, S. (1998). Writing System and languages of the world. Retrieved July 24, 2008, from http://omniglot.com/writing/definition.htm

[2] Dawn M. Zimmaro (2003). Writing Effective Examinations. Document for workshop at The University of Texas at Austin

[3] Hoang Van Van et al. (6 $6^{\text {th }}$ edition). TiếngAnh 10. Viet Nam Education Publishing House

[4] Hoang Van Van et al. (2 ${ }^{\text {th }}$ edition). TiếngAnh 11. Viet Nam Education Publishing House 
[5] Hoang Van Van et al. (4 ${ }^{\text {th }}$ edition). TiếngAnh 12. Viet Nam Education Publishing House

[6] Huot, B. (1990). Reliability, validity, and holistic scoring: What we know and what we need to know. College Composition and Communication, 41, 201-13.

www.questia.com/PM.qst?a=o\&se $=$ gglsc \& $\mathrm{d}=5001398251$

[7] TunkuMohaniTunkuMohtar. (2000). Dilemmas in Test Construction: Quest and

\section{ISSN 2455-6378}

Questions, in Anthology Series 45: Teaching and Assessing language proficiency. RELC

[8] Vu Thi Phuong Anh (1997). Authenticity and Validity in language testing: investigating the reading components of IELTS and TOEFL. Unpublished thesis of Doctor of Philosophy. Australia: La Trobe University 